\title{
Hydrothermal Sulfonation of Palm Empty Fruit Bunch Carbon as Solid Acid Catalyst and Its Hydrolysis Catalytic Activity
}

Iryanti F. Nata ( $\square$ ifnata@ulm.ac.id)

Lambung Mangkurat University https://orcid.org/0000-0003-2610-4513

Chairul Irawan

Universitas Lambung Mangkurat

Meilana D. Putra

Universitas Lambung Mangkurat

Cheng-Kang Lee

National Taiwan University of Science and Technology

\section{Research}

Keywords: cassava, hydrolysis, palm oil, sulfonated, solid acid

Posted Date: August 10th, 2020

DOI: https://doi.org/10.21203/rs.3.rs-53551/v1

License: (a) (i) This work is licensed under a Creative Commons Attribution 4.0 International License.

Read Full License 


\section{Abstract}

The sulfonated carbon solid acid catalyst $\left(\mathrm{C}-\mathrm{SO}_{3} \mathrm{H}\right)$ was successfully generated from palm empty fruit bunch (PEFB) carbon via hydrothermal sulfonation by addition of hydroxyethylsulfonic acid and citric acid. The $\mathrm{C}-\mathrm{SO}_{3} \mathrm{H}$ was identified contain of $1.75 \mathrm{mmol} / \mathrm{g}$ of acidity and $40.2 \%$ of sulphur. The surface morphology of $\mathrm{C}-\mathrm{SO}_{3} \mathrm{H}$ showed pores with diameters of 3-6 $\mu \mathrm{m}$ and crystalline index (Crl) of material was decreased to $63.8 \%$ due to changed structure become carbon. The surface area of carbon was increased significantly from 11.5 to $239.65 \mathrm{~m}^{2} \mathrm{~g}^{-1}$ after hydrothermal treatment. The identification of functional groups of $-\mathrm{SO}_{3} \mathrm{H}, \mathrm{COOH}$ and $-\mathrm{OH}$ were detected by Fourier Transform Infra-Red (FT-IR). The optimum catalytic activity of $\mathrm{C}-\mathrm{SO}_{3} \mathrm{H}$ was achieved via hydrolysis reaction with $60.4 \%$ of total reducing sugar (TRS) yield. The both concentrations of $\mathrm{C}-\mathrm{SO}_{3} \mathrm{H}$ and cassava peel starch is $5 \%$ at $100{ }^{\circ} \mathrm{C}$ for $1 \mathrm{~h}$. Stability of $\mathrm{C}-\mathrm{SO}_{3} \mathrm{H}$ showed good performance for $4^{\text {th }}$ repeated used; it showed insignificant of activity that decreased only of $6 \%$. Thus, the $\mathrm{C}-\mathrm{SO}_{3} \mathrm{H}$ is a candidate for green and potential sulfonated solid acid catalyst for wide range applications.

\section{Introduction}

In recent years, the interest in bioconversion of lignocellulosic waste materials to chemicals and fuels has been steadily increasing because of their abundance, low cost, and sustainability $(1,2)$. One of the worldwide highest production of vegetable oil is crude palm oil with the amount of $6.93 .10^{7}$ tons on 2017 (3). Palm empty fruit bunch (PEFB) is one of the main waste products obtained from oil palm industry and it's mainly causing of pollution. Concern about environmental protection has increased over the year from a global viewpoint. The utilization of oil palm industry leads to generate large amount of solids wastes i.e., PEFBs; these are utilized as mulch for preventing erosion maintain soil moisture, fertilizer and compost. On the other hand, the PEFB has a little commercial value and even became a disposable problem due to the low bulk density thus needing large storage volume. The PEFB is usually used as a fuel in the factory in which every ton of FFBs processed in the mills consist of $23 \%$ of PEFB, $12 \%$ of mesocarp fiber, and $5 \%$ of shell $5 \%(4)$.

PEFB consist potential component of $44.4 \%$ of cellulose; $30.9 \%$ of hemicelluloses, and $14.2 \%$ of lignin that could be utilized for more useful products $(5,6)$. Due to the high content of biomass, many researchers have investigated the utilization of PEFB such as biodiesel (7), biogas (8), ethanol and nanocomposites (9) and other value-added products $(6,10,11)$. However, there is increasing concern to utilize PEFBs with low cost of process.

Many researchers have tried to produce low cost activated carbons as adsorbent using oil palm shell (12), palm fiber (13) and other carbon (14). Enrich-solid carbon could be produced via hydrothermal method by modifying the carbon surface through one-step reaction $(11,15)$. In addition, no research has been found that utilized the PEFBs in term of its conversion to solid acid catalyst. Solid acid catalysis is type of catalyst which is economically and ecologically applied in catalysis. The catalyst has many 
advantages compared to the common liquid acid catalysts such as fewer disposal problems, noncorrosive, reusable, environmentally benign and easy handling. Newly, incomplete carbonization of sugars during preparation of sulfonated carbon was reported; the process resulted in a better catalytic activity on synthesis of biodiesel compared with other solid acid catalyst, including sulfonated zirconia, nafion, and niobic acid (16). Catalytic reactions based on solid acid catalyst by using reactant such as glycerol (17), cellulose (18), hemicelluloses (19) and starch (20) have been confirmed as an effective catalyst. On the other hand, the acid content on the catalysts depend on the carbon structure as precursor which effect to performance in catalytic reaction. To increase the performance, it is likely to sulfonate functionalization or deposit other functional group on the carbon chains due to morphology structure of PFEB is having pore along the fibers.

Based on our knowledge, no research has been reported for preparation of high sulfonated carbon solid acid catalyst from carbonized of PEFB via hydrothermal treatment. Herein, the facile preparation of sulfonated solid acid catalyst based on PEFB was conducted. Formation of carbon materials and the sulfonation process are expected to result in high acid content. In this work, the effect of sulfonation process on the structure of carbon was evaluated. Physical properties of functionalization of biocarbon $\left(\mathrm{C}-\mathrm{SO}_{3} \mathrm{H}\right)$ such as the morphology, crystalline structure, surface functionalization, and surface area were characterized. The $\mathrm{C}-\mathrm{SO}_{3} \mathrm{H}$ formed catalyst was applied for hydrolysis of cassava peel starch. Moreover, the utilization of cassava peel as substrate is also one of strategy to cover the problem of waste food becoming value-added. The reusability of $\mathrm{C}-\mathrm{SO}_{3} \mathrm{H}$ was also investigated to evaluate the catalyst performance. This research can be useful in the catalyst field and more take attention on environmental benign; especially using waste biomass material.

\section{Materials And Methods}

\subsection{Material}

Palm empty fruit bunch and cassava peel were collected from PT. Pola Kahuripan Inti Sawit, Kintapura, South Kalimantan, Indonesia and from traditional local market, respectively. The D-glucose $\left(\mathrm{C}_{6} \mathrm{H}_{12} \mathrm{O}_{6}\right)$, citric acid $\left(\mathrm{C}_{6} \mathrm{H}_{5} \mathrm{Na}_{3} \mathrm{O}_{7} .2 \mathrm{H}_{2} \mathrm{O}\right)$, 3,5-dinitrosalicylic acid $\left(\mathrm{C}_{7} \mathrm{H}_{4} \mathrm{~N}_{2} \mathrm{O}_{7}\right)$, hydroxyethylsulfonic acid $\left(\mathrm{C}_{2} \mathrm{H}_{6} \mathrm{O}_{4} \mathrm{~S}\right)$, phenolphthalein $\left(\mathrm{C}_{20} \mathrm{H}_{14} \mathrm{O}_{4}\right)$, sodium hydroxide $(\mathrm{NaOH})$, methanol $\left(\mathrm{CH}_{3} \mathrm{OH}\right)$, sodium chloride $(\mathrm{NaCl})$, chloride acid $(\mathrm{HCl})$, sulfuric acid $\left(\mathrm{H}_{2} \mathrm{SO}_{4}\right)$ and oxalic acid $\left(\mathrm{H}_{2} \mathrm{C}_{2} \mathrm{O}_{4}\right)$ were purchased from Sigma-Aldrich.

\subsection{Preparation of sulfonated carbon solid acid catalyst}

The PEFB was washed with tape water and further dried in oven at $100^{\circ} \mathrm{C}$, then grounded into powder by a high speed blender to gain a size material pass off sieve 60 mesh. PEFB (500 g) was heated in the furnace at $350^{\circ} \mathrm{C}$ for $30 \mathrm{~min}$. The obtain carbon (C) was through the sulfonation process by hydrothermal treatment according to the procedure (21) with a little modification. Briefly, $1.5 \mathrm{~g}$ of citric acid, $2.5 \mathrm{~g}$ of hydroxyethylsulfonic acid and $30 \mathrm{~g}$ of carbon were poured into $40 \mathrm{~mL}$ of deionized water; this solution was then placed in Teflon-lined Stainless Steel autoclave $(50 \mathrm{~mL})$. Reaction took place at 
$180^{\circ} \mathrm{C}$ for $4 \mathrm{~h}$ in an oven. The carbon materials were obtained after filtration process and consecutive washing process of using DI water, methanol and DI water. The product $\left(\mathrm{C}-\mathrm{SO}_{3} \mathrm{H}\right)$ continued to dry at 80 ${ }^{\circ} \mathrm{C}$ overnight in an oven.

\subsection{Preparation of cassava peel starch and hydrolysis reaction}

Cassava peel starch was prepared by blended small size of cassava peel $(2 \times 2 \mathrm{~cm})$ after cleaning process was conducted with tape water in the presence of DI water (ratio 1:4). After filtration, the precipitate was dried for $24 \mathrm{~h}$ at $90^{\circ} \mathrm{C}$ in oven and then sieved to pass 40 mesh. The hydrolysis of cassava peel starch $(2.5 ; 5.0 ; 7.5 ; 10 \%, \mathrm{w} / \mathrm{v})$ was conducted in reactor $(50 \mathrm{~mL})$ with the addition of $\mathrm{C}-\mathrm{SO}_{3} \mathrm{H}(2.5 ; 5.0 ; 7.5 ; 10 \%$, $\mathrm{w} / \mathrm{v})$ and distilled water $(50 \mathrm{~mL})$ at $100{ }^{\circ} \mathrm{C}$ for $60 \mathrm{~min}$. Hydrolysis product was obtained by centrifugation; the analysis of an aliquot of solution was conducted by using DNS method with 3,5-dinitrosalicylic acid to measure total reducing sugar (22). To examine the catalyst performance, the concentrated sulfuric acid as common homogeneous catalyst and the carbon without sulfonation process as general heterogeneous catalyst were also tested for catalytic reaction. All data are presented in averages of experiments results in triplicate.

\subsection{Characterizations}

Neutralization titration method was used to calculate Brǿnsted acid sites on C-SO ${ }_{3} \mathrm{H}(23)$. Briefly, carbon $(80 \mathrm{mg})$ and solution of $1 \mathrm{M} \mathrm{NaCl}(40 \mathrm{~mL})$ was mixed with stirring for $6 \mathrm{~h}$ and at room temperature. After centrifugation process and then titrated by $0.01 \mathrm{~N} \mathrm{NaOH}$, the supernatant was obtained. Phenolphthalein was utilized as an indicator. The X-Ray Fluorescence (XRF) observation was used for detecting element in the sample by PANalytical/Minipal machine. Surface area of materials was calculated using BrunauerEmmet-Teller (BET) characterization by Quantachrome, Autosorb-1 instrument with nitrogen adsorptiondesorption type. The scanning electron microscope with type of JEOL, JSM-6500 LV was utilized to analyze the surface morphology. The X-ray diffractometer with Rigaku D/MAX-B model equipped with Copper K-alpha ( $\mathrm{Cu} \mathrm{Ka)} \mathrm{radiation} \mathrm{machine} \mathrm{was} \mathrm{used} \mathrm{for} \mathrm{X-ray} \mathrm{diffraction} \mathrm{(XRD)} \mathrm{measurement.} \mathrm{The}$ number of $40 \mathrm{kV}$ and $100 \mathrm{~mA}$ were used for operation of voltage and current, respectively. The Fourier transform infrared spectrometry (FT-IR, Bio-rad, Digilab FTS-3500) was utilized for analyzing the functional groups on carbon surface. The thermal gravimetric analysis (TGA) was conducted to monitor the weight loss of the samples at temperature range of $30^{\circ} \mathrm{C}$ to $600^{\circ} \mathrm{C}$; this process was flowed with nitrogen at the specific heating rate of $10^{\circ} \mathrm{C} \mathrm{min}-1$ (Perkin Elmer, Diamond TG/DTA). The carbon content in the particles and degradation of component were calculated by weight loss percentage from TGA curves. Total reducing sugar (TRS) was analyzed by using 3,5-dinitrosalicylic acid (DNS) method (22) by using UV-Vis spectroscopy with type V-550-JASCO.

\section{Results And Discussion}

\subsection{Characterization of sulfonated solid acid catalyst}


The formation of $\mathrm{C}-\mathrm{SO}_{3} \mathrm{H}$ catalyst was conducted through two steps reaction. First, fibre of PEFB was carbonized to produce black carbon. Second step is sulfonation of carbon by hydrothermal treatment. The all preparation steps of $\mathrm{C}-\mathrm{SO}_{3} \mathrm{H}$ generated from PEFB are presented in Figure 1.

Material changes of morphology structures were observed by SEM (Figure 2); it can be seen that the original structure of PEFB fibre was fibrous and smooth surface. The PEFB consisted of cellulose, hemicelluloses and lignin that still bind to each other (Figure 2a). The PEFB started to be pyrolyzed, continued by dehydration and dissociation process of -C-O-C-; then last step is polycyclic aromatic carbon rings formation at $350^{\circ} \mathrm{C}$ and finally form carbon structure $(24,25)$. After carbonization, surface structure was coarse and porous. This was possible due to the heating process during carbonization causing the cellulose, hemicelluloses and lignin compounds to break into 3 main components of carbon, tar and gas (volatile matter) (Figure $2 \mathrm{~b}$ ). The sulfonation process by hydrothermal carbonization (HTC) treatment has led to the surface of carbon becoming more porous with diameters of 3-6 $\mu \mathrm{m}$ (Figure 2c); this contained of sulfonate and carboxylic group.

HTC system is spontaneous process and an exothermic reaction with vast majority of the carbon. A low temperature of $\mathrm{HTC}$ operated at over $100^{\circ} \mathrm{C}$ is widely found in nature because many minerals formed under these circumstances. The process to form carbon materials via hydrothermal condition led to the increased solubility, facilitating the physical and chemical interaction between reagents and solvent and also ionic and acid reaction to form structure of carbonaceous (26). The HTC process enhanced the acidity level of the $\mathrm{C}-\mathrm{SO}_{3} \mathrm{H}$ up to 7.3 -fold than its level of $\mathrm{C}$. Compared to $\mathrm{C}$, the surface area of $\mathrm{C}-\mathrm{SO}_{3} \mathrm{H}$ was also significantly increased from 11.5 to $239.65 \mathrm{~m}^{2} \mathrm{~g}^{-1}$. The nitrogen adsorption-desorption isotherms for $\mathrm{C}$ and $\mathrm{C}-\mathrm{SO}_{3} \mathrm{H}$ was illustrated in Figure 3. The carbon material exhibited type IV isotherm with $\mathrm{H} 3$-type hysteresis loop, which was indicating the mesoporous structure of the $\mathrm{C}-\mathrm{SO}_{3} \mathrm{H}$. Besides, the $\mathrm{C}-\mathrm{SO}_{3} \mathrm{H}$ more stable and water-tolerant in hydrothermal conditions than other solid acid catalyst (23).

The sulfonic acid group was reached through a reaction of sulfonating agent and aromatic rings resulting in a structure of carbon with the electrophilic substitution $(27,28)$. It was reported that the surface functionalization by sulfonate group on polycyclic aromatic carbon rings would generate a large amount of acid sites with form of thermally stable; furthermore, the sulfonic groups was stacked at the edge of carbon ring (29). The XRF analysis detected the sulphur content on carbon about $40.2 \%$. The sulfonated carbon solid acid catalyst was successfully to form amorphous structure; this type of structure was composed of polycyclic aromatic carbon sheets with sulfonate and carboxylic group. The detail result of characterization of PEFB, C, and $\mathrm{C}-\mathrm{SO}_{3} \mathrm{H}$ are presented in Table 1.

Table 1. The characterization of PFEB fiber, $\mathrm{C}$, and $\mathrm{C}-\mathrm{SO}_{3} \mathrm{H}$ 


\begin{tabular}{|c|c|c|c|c|c|c|}
\hline \multirow[t]{2}{*}{ Sample } & \multicolumn{4}{|c|}{ Component (\%) } & \multirow{2}{*}{$\begin{array}{l}\text { Acidity } \\
\left(\mathrm{mmol} \mathrm{g}^{-1}\right)\end{array}$} & \multirow{2}{*}{$\begin{array}{l}\text { Surface area } \\
\left(\mathrm{m}^{2} \mathrm{~g}^{-1}\right)\end{array}$} \\
\hline & $\mathrm{Ca}$ & $\mathrm{K}$ & $\mathrm{Si}$ & $S$ & & \\
\hline PEFB fiber & 36.0 & 46.9 & 6.5 & - & - & 0.171 \\
\hline C & 30.1 & 53.9 & 4.8 & - & 0.21 & 11.55 \\
\hline $\mathrm{C}-\mathrm{SO}_{3} \mathrm{H}$ & 13.3 & 7.16 & 10.0 & 40.2 & 1.75 & 239.65 \\
\hline
\end{tabular}

The crystalline index is the level of regularity of the crystal structure of a material; the breaking structure of PEFB was also proven by a decrease of crystalline index of $63.8 \%$ (Figure 4). The XRD pattern shows the changes of intensity on amorph area at $2 \theta=17^{\circ}$ and cellulose crystals at $2 \theta=22.8^{\circ}(30)$. The decrease in the $\mathrm{Crl}$ number because the crystal structure has been lost and converted into carbon structure during carbonization process. The high intensity of cellulose crystal area was only found for PEFB. The similar results in the carbon and sulfonated solid acid catalyst were observed indicating no structure change during sulfonation treatment.

Figure 5 presents the spectra of FT-IR for PEFB, C, and $\mathrm{C}_{-} \mathrm{SO}_{3} \mathrm{H}$. After sulfonation process, the appearance of bands at $1207 \mathrm{~cm}^{-1}$ and $1720 \mathrm{~cm}^{-1}$ were recorded due to sulfonic group; the presence of sulfonation was also confirmed elsewhere (31). The band observed at $3400 \mathrm{~cm}^{-1}$ was attributed to $-\mathrm{OH}$ in carboxylic acids; this indicated that the sulfonation process not only created sulfonic groups but also formed other functional groups because of oxidizing reaction (32). The $\mathrm{C}=\mathrm{C}$ bond in polyaromatic compounds was observed at $1608 \mathrm{~cm}^{-1}$ that was assigned as carbonized material.

Thermal gravimetric analysis was conducted to study the thermal degradation type of material and impact of sulfonation on $\mathrm{C}-\mathrm{SO}_{3} \mathrm{H}$. Figure 6 showed the thermal gravimitric of materials carbonized up to $600^{\circ} \mathrm{C}$. The dehydration of water for PEFB sample was started at $74.4^{\circ} \mathrm{C}$, continued by decomposition of hemicellulose and lignin at $332.5^{\circ} \mathrm{C}$. For both materials, the reduction of mass was due to the decomposition of carbon and thermal process also enhanched the oxidized structure thus thermal stability was reduced (24). TGA curve also shows the mass loss trend of $\mathrm{C}_{-} \mathrm{SO}_{3} \mathrm{H}$ about more $8 \%$ than that of $\mathrm{C}$. At higher temperature, the material was rapidly degradated especially for $\mathrm{C}-\mathrm{SO}_{3} \mathrm{H}$; this is possible related to the amount of sulfonate group on carbon. As reported, the $\mathrm{C}-\mathrm{SO}_{3} \mathrm{H}$ sulfonated by sulfonate group have a weak structure and unstable condition on range of temperature compared to original carbon (33).

\subsection{Hydrolysis of cassava peel starch over sulfonated carbon solid acid catalyst}

One of potential material for glucose production is carbohydrate; it could be converted to glucose by hydrolysis reaction using heterogeneous or homogeneous catalyst and enzymatic reaction. The cassava peel starch which was used in this research consists of $80.2 \%$ of carbohydrate. The hydrolysis 
performance with variation of catalyst concentration was presented in Figure 6. The TRS as hydrolysis product was increased when $\mathrm{C}-\mathrm{SO}_{3} \mathrm{H}$ weight increased up to $5 \%$ with TRS of $4.139 \mathrm{mg} \mathrm{mL}^{-1}$. The presence of $\mathrm{C}-\mathrm{SO}_{3} \mathrm{H}$ as catalyst on cassava peel starch hydrolysis significantly increased the product about $316.7 \%$ compared than hydrolysis without catalyst. It means that the catalytic performance of C$\mathrm{SO}_{3} \mathrm{H}$ increased due to modified surface functionalization. The concentration of TRS regularly decreased at higher $\mathrm{C}-\mathrm{SO}_{3} \mathrm{H}$ concentration ( $>5 \%$ ); it was because the formed sugar compounds was degraded become to furfural compounds (34). The performance of $\mathrm{C}-\mathrm{SO}_{3} \mathrm{H}$ in hydrolysis was observed to be higher TRS compared with those sulfonated catalyst about $0.639 \mathrm{mg} \mathrm{mL}^{-1}$ (35). The TRS produced was also indicated by color intensity; the DNS assay was used to evaluate the intensity. The color of solution was obtained to more orange and higher color intensity showed higher concentration of TRS detected (Figure 7, inset).

The highest TRS concentration was obtained because catalyst have access and easily to attach the carbohydrate linkage. Furthermore, concentration of cassava peel starch as substrate also has optimum condition at $5 \%$ to produce TRS (Figure 8). Higher concentration of starch would lead to more viscous solution due to swelling and gelatinization of starch in the presence of water. Thus, this condition caused the $\mathrm{C}-\mathrm{SO}_{3} \mathrm{H}$ more difficult to access the carbohydrate linkage; hence, lower TRS was produced. Based on energy efficiency and consumption cost for hydrolysis reaction, the concentration $5 \%$ of cassava peel starch using $5 \%$ of $\mathrm{C}-\mathrm{SO}_{3} \mathrm{H}$ was selected as optimum condition.

In order to know the reactivity of $\mathrm{C}-\mathrm{SO}_{3} \mathrm{H}$, it is interesting to investigate the $\mathrm{C}$ and $\mathrm{H}_{2} \mathrm{SO}_{4}$ performance as heterogeneous and homogeneous catalyst, respectively. The $\mathrm{C}$ was used as a control; whereas, the $\mathrm{H}^{+}$ ions concentration on $\mathrm{H}_{2} \mathrm{SO}_{4}$ used was the same concentration with the $\mathrm{H}^{+}$ion content on $\mathrm{C}-\mathrm{SO}_{3} \mathrm{H}$. As shown in Figure 9, the TRS about $2.05 \mathrm{mg} / \mathrm{mL}$ and $3.18 \mathrm{mg} / \mathrm{mL}$ were obtained when using $\mathrm{C}$ dan $\mathrm{H}_{2} \mathrm{SO}_{4}$ as catalyst, respectively. The process using $\mathrm{C}^{-\mathrm{SO}_{3}} \mathrm{H}$ catalyst had higher value of TSR about 1.02-fold than that using $\mathrm{C}$. On the other hand, the common liquid catalyst $\left(\mathrm{H}_{2} \mathrm{SO}_{4}\right)$ showed lower performance (TRS value of $3.18 \mathrm{mg} / \mathrm{mL}$ ) compared to $\mathrm{C}-\mathrm{SO}_{3} \mathrm{H}$. It is probably due to presence of $-\mathrm{SO}_{3} \mathrm{H}$ and $-\mathrm{COOH}$ groups that were functionalized on carbon. Furthermore, the $\mathrm{H}_{2} \mathrm{SO}_{4}$ only have $\mathrm{H}^{+}$ions in homogenous phase and the catalyst accessibility should be easier to attach carbohydrate linkage.

Table 2 shows that the sulfonated carbon solid acid catalyst prepared in this work is more efficient and had higher hydrolysis activity than other sulfonated solid catalysts; even, they used difficult method of ionic liquid or water with HTC and microwave method.

Table 2. Sulfonated solid acid on hydrolysis catalytic activity 


\begin{tabular}{|lllllll|}
\hline Catalyst & $\begin{array}{l}\text { Acidity (mmol } \\
\left.\mathrm{g}^{-1}\right)\end{array}$ & Solvent & Method & $\begin{array}{l}\text { Temp (K)/Time } \\
(\mathrm{h})\end{array}$ & $\begin{array}{l}\text { TRS yield } \\
(\%)\end{array}$ & Ref. \\
\hline $30-\mathrm{CCSA}$ & 0.86 & $\mathrm{H}_{2} \mathrm{O}$ & $\mathrm{HTC}$ & $423 / 6$ & 44.52 & $(36)$ \\
\hline $\begin{array}{l}\mathrm{PCPs}- \\
\mathrm{SO}_{3} \mathrm{H}\end{array}$ & 1.80 & $\mathrm{H}_{2} \mathrm{O}$ & - & $393 / 3$ & 5.30 & $(37)$ \\
$\mathrm{CM}^{-\mathrm{SO}_{3} \mathrm{H}}$ & 4.22 & $\begin{array}{l}{[\mathrm{BMIM}]} \\
{[\mathrm{Cl}]}\end{array}$ & - & $303 / 3$ & 59.4 & $(38)$ \\
\hline $\begin{array}{l}\mathrm{CSA}^{-} \\
\mathrm{SO}_{3} \mathrm{H}\end{array}$ & 1.76 & $\mathrm{H}_{2} \mathrm{O}$ & Microwave & $403 / 1$ & 34.6 & $(39)$ \\
\hline $\mathrm{C}^{-\mathrm{SO}_{3} \mathrm{H}}$ & 1.75 & $\mathrm{H}_{2} \mathrm{O}$ & - & $373 / 1$ & 64.0 & This \\
\hline
\end{tabular}

In order to investigate the activity of catalyst in repeated uses, the recovered $\mathrm{C}-\mathrm{SO}_{3} \mathrm{H}$ was rinsed $3^{\text {rd }}$ times with DI water by stirred for $45 \mathrm{~min}$ and collected after separation with liquid and then dried. The recovered catalyst performance was observed to be slight lower than that was obtained in the $1^{\text {st }}$ reaction. TRS decrease was observed only $6 \%$ after $4^{\text {th }}$ repeated uses (Figure 10 ). This proves that the $\mathrm{C}-\mathrm{SO}_{3} \mathrm{H}$ provide effectively to hydrolyze the starch into glucose. This result also shows that the prepared $\mathrm{C}-\mathrm{SO}_{3} \mathrm{H}$ not only provide non-toxic materials, green process and easy handling, but also has good catalytic performance for hydrolysis reaction.

\section{Conclusions}

The high content of acidity, rich in sulfonate and carboxyl group on carbon materials could be synthesized by hydrothermal treatment by addition of hydroxyethylsulfonic and citric acid. The good performance on hydrolysis and stability reaction were shown after 4th repeated used. Simple operation, high catalytic activity and waste materials as precursor are the important key for development of sulfonated solid acid catalyst. The synthesized catalyst has high potential to be developed for green process in various catalytic applications.

\section{Declarations}

\section{Availability of data and materials}

All data used to support the findings of this study are available from the corresponding author.

\section{Competing interests}

The authors declare they have no competing interests. 


\section{Funding}

This work was supported by Directorate General of Research and Community Services, Ministry of Research, Technology and Higher Education, Republic of Indonesia that provided Research Grand (contract No. 122.9/UN8.2/PP/2019).

\section{Authors' contributions}

All authors read and approved the final manuscript

\section{Acknowledgements}

The authors wish to thank to Directorate General of Research and Community Services, Ministry of Research, Technology and Higher Education, Republic of Indonesia that provided Research Grand (contract No. 122.9/UN8.2/PL/2019).

\section{References}

1. Sun Z, Bottari G, Afanasenko A, Stuart MCA, Deuss PJ, Fridrich B, et al. Complete lignocellulose conversion with integrated catalyst recycling yielding valuable aromatics and fuels. Nature Catalysis. 2018;1(1):82-92.

2. Sae-ngae S, Cheirsilp B, Louhasakul Y, Suksaroj TT, Intharapat P. Techno-economic analysis and environmental impact of biovalorization of agro-industrial wastes for biodiesel feedstocks by oleaginous yeasts. Sustainable Environment Research. 2020;30(1):11.

3. Ocampo Batlle EA, Castillo Santiago Y, Venturini OJ, Escobar Palacio JC, Silva Lora EE, Yepes Maya DM, et al. Thermodynamic and environmental assessment of different scenarios for the insertion of pyrolysis technology in palm oil biorefineries. Journal of Cleaner Production. 2020;250:119544.

4. Najafpour G, Yieng HA, Younesi H, Zinatizadeh A. Effect of organic loading on performance of rotating biological contactors using Palm Oil Mill effluents. Process Biochemistry. 2005;40(8):287984.

5. Fahma F, Iwamoto S, Hori N, Iwata T, Takemura A. Isolation, preparation, and characterization of nanofibers from oil palm empty-fruit-bunch (OPEFB). Cellulose. 2010;17(5):977-85.

6. Ndubuisi-Nnaji UU, Ofon UA, Ekponne NI, Offiong N-AO. Improved biofertilizer properties of digestate from codigestion of brewer's spent grain and palm oil mill effluent by manure supplementation. Sustainable Environment Research. 2020;30(1):14.

7. Yaakob Z, Sukarman ISB, Narayanan B, Abdullah SRS, Ismail M. Utilization of palm empty fruit bunch for the production of biodiesel from Jatropha curcas oil. Bioresource Technology. 2012;104(0):695-700.

8. O-Thong S, Boe K, Angelidaki I. Thermophilic anaerobic co-digestion of oil palm empty fruit bunches with palm oil mill effluent for efficient biogas production. Applied Energy. 2012;93(0):648-54. 
9. Saba N, Paridah MT, Abdan K, Ibrahim NA. Physical, structural and thermomechanical properties of oil palm nano filler/kenaf/epoxy hybrid nanocomposites. Materials Chemistry and Physics. 2016;184:64-71.

10. Loh SK, James S, Ngatiman M, Cheong KY, Choo YM, Lim WS. Enhancement of palm oil refinery waste - Spent bleaching earth (SBE) into bio organic fertilizer and their effects on crop biomass growth. Industrial Crops and Products. 2013;49(0):775-81.

11. Parshetti GK, Kent Hoekman S, Balasubramanian R. Chemical, structural and combustion characteristics of carbonaceous products obtained by hydrothermal carbonization of palm empty fruit bunches. Bioresource Technology. 2013;135:683-9.

12. Foo KY, Hameed BH. Preparation of oil palm (Elaeis) empty fruit bunch activated carbon by microwave-assisted $\mathrm{KOH}$ activation for the adsorption of methylene blue. Desalination. 2011;275(13):302-5.

13. Hameed BH, Tan IAW, Ahmad AL. Optimization of basic dye removal by oil palm fibre-based activated carbon using response surface methodology. Journal of Hazardous Materials. 2008;158(2-3):324-32.

14. Zhang X-H, Tang Q-Q, Yang D, Hua W-M, Yue Y-H, Wang B-D, et al. Preparation of poly(pstyrenesulfonic acid) grafted multi-walled carbon nanotubes and their application as a solid-acid catalyst. Materials Chemistry and Physics. 2011;126(1):310-3.

15. Merzari F, Lucian M, Volpe M, Andreottola G, Fiori L. Hydrothermal carbonization of biomass: design of a bench-scale reactor for evaluating the heat of reaction. Chemical Engineering Transaction. 2018;65:43-8.

16. Xiao H, Guo Y, Liang X, Qi C. One-step synthesis of novel biacidic carbon via hydrothermal carbonization. Journal of Solid State Chemistry. 2010;183(7):1721-5.

17. Han W, Li X, Yu S, Sang X. Catalytic action of biomass carbon sulfoacid in fine organic synthesis. Chemical Engineering Transactions. 2018;65:547-52.

18. Li OL, Ikura R, Ishizaki T. Hydrolysis of cellulose to glucose over carbon catalysts sulfonated via a plasma process in dilute acids. Green Chemistry. 2017;19(20):4774-7.

19. Dhepe PL, Sahu R. A solid-acid-based process for the conversion of hemicellulose. Green Chemistry. 2010;12(12):2153-6.

20. Yamaguchi D, Hara M. Starch Saccharification by Carbon-Based Solid Acid Catalyst. Solid State Sciences. 2010;12(6):1018-23.

21. Xiao H, Guo Y, Liang X, Qi C. One-step synthesis of novel biacidic carbon via hydrothermal carbonization. Journal of Solid State Chemistry. 2010;183:1721-5.

22. Miller G. Use of Dinitrosalicylic Acid Reagent for Determination of Reducing Sugar. Analyt Chem. 1959;31:426-8.

23. Onda A, Ochi T, Yanagisawa K. Selective hydrolysis of Cellulose into glucose over solid acid catalyst. Green Chemistry. 2008;10:1033-7. 
24. Kastner JR, Miller J, Geller DP, Locklin J, Keith LH, Johnson T. Catalytic esterification of fatty acids using solid acid catalysts generated from biochar and activated carbon. Catalysis Today. 2012;190(1):122-32.

25. Fraga AdC, Quitete CPB, Ximenes VL, Sousa-Aguiar EF, Fonseca IM, Rego AMB. Biomass derived solid acids as effective hydrolysis catalysts. Journal of Molecular Catalysis A: Chemical. 2016;422:248-57.

26. Hu B, Wang K, Wu L, Yu S-H, Antonietti M, Titirici M-M. Engineering Carbon Materials from the Hydrothermal Carbonization Process of Biomass. Advanced Materials. 2010;22(7):813-28.

27. Aldana-Pérez A, Lartundo-Rojas L, Gómez R, Niño-Gómez ME. Sulfonic groups anchored on mesoporous carbon Starbons-300 and its use for the esterification of oleic acid. Fuel. 2012;100:12838.

28. Lokman IM, Goto M, Rashid U, Taufiq-Yap YH. Sub- and supercritical esterification of palm fatty acid distillate with carbohydrate-derived solid acid catalyst. Chemical Engineering Journal. 2016;284:8728.

29. Okamura M, Takagaki A, Toda M, Kondo JN, Domen K, Tatsumi T, et al. Acid-catalyzed reactions on flexible polycyclic aromatic carbon in amorphous carbon. Chemistry of Materials. 2006;18(13):303945.

30. Zhao H, Kwak JH, Conrad Zhang Z, Brown HM, Arey BW, Holladay JE. Studying cellulose fiber structure by SEM, XRD, NMR and acid hydrolysis. Carbohydrate Polymers. 2007;68(2):235-41.

31. Ormsby R, Kastner JR, Miller J. Hemicellulose hydrolysis using solid acid catalysts generated from biochar. Catalysis Today. 2012;190(1):89-97.

32. Santos EM, Teixeira APdC, da Silva FG, Cibaka TE, Araújo MH, Oliveira WXC, et al. New heterogeneous catalyst for the esterification of fatty acid produced by surface aromatization/sulfonation of oilseed cake. Fuel. 2015;150:408-14.

33. Ma'rifah YN, Nata IF, Wijayanti H, Mirwan A, Irawan C, Putra MD, et al. One-step Synthesis to Enhance the Acidity of a Biocarbon-Based Sulfonated Solid Acid Catalyst. International Journal of Technology. 2019;10(3):512-20.

34. Palmqvist E, Hahn-Hägerdal B. Fermentation of lignocellulosic hydrolysates. II: inhibitors and mechanisms of inhibition. Bioresource Technology. 2000;74(1):25-33.

35. Nata IF, Putra MD, Nurandini D, Irawan C. Facile Strategy for Surface Functionalization of Corn Cob to Biocarbon and Its Catalytic Performance on Banana Peel Starch Hydrolysis International Journal on Advanced Science Engineering Information Technology. 2017;7:1302-8.

36. Shen S, Cai B, Wang C, Li H, Dai G, Qin H. Preparation of a novel carbon-based solid acid from cocarbonized starch and polyvinyl chloride for cellulose hydrolysis. Applied Catalysis A: General. 2014;473:70-4.

37. Guo H, Lian Y, Yan L, Qi X, Smith RL. Cellulose-derived superparamagnetic carbonaceous solid acid catalyst for cellulose hydrolysis in an ionic liquid or aqueous reaction system. Green Chemistry. 2013;15(8):2167-74. 
38. Qi X, Lian Y, Yan L, Smith RL. One-step preparation of carbonaceous solid acid catalysts by hydrothermal carbonization of glucose for cellulose hydrolysis. Catalysis Communications. 2014;57:50-4.

39. Jiang Y, Li X, Wang X, Meng L, Wang H, Peng G, et al. Effective saccharification of lignocellulosic biomass over hydrolysis residue derived solid acid under microwave irradiation. Green Chemistry. 2012;14(8):2162-7.

\section{Figures}

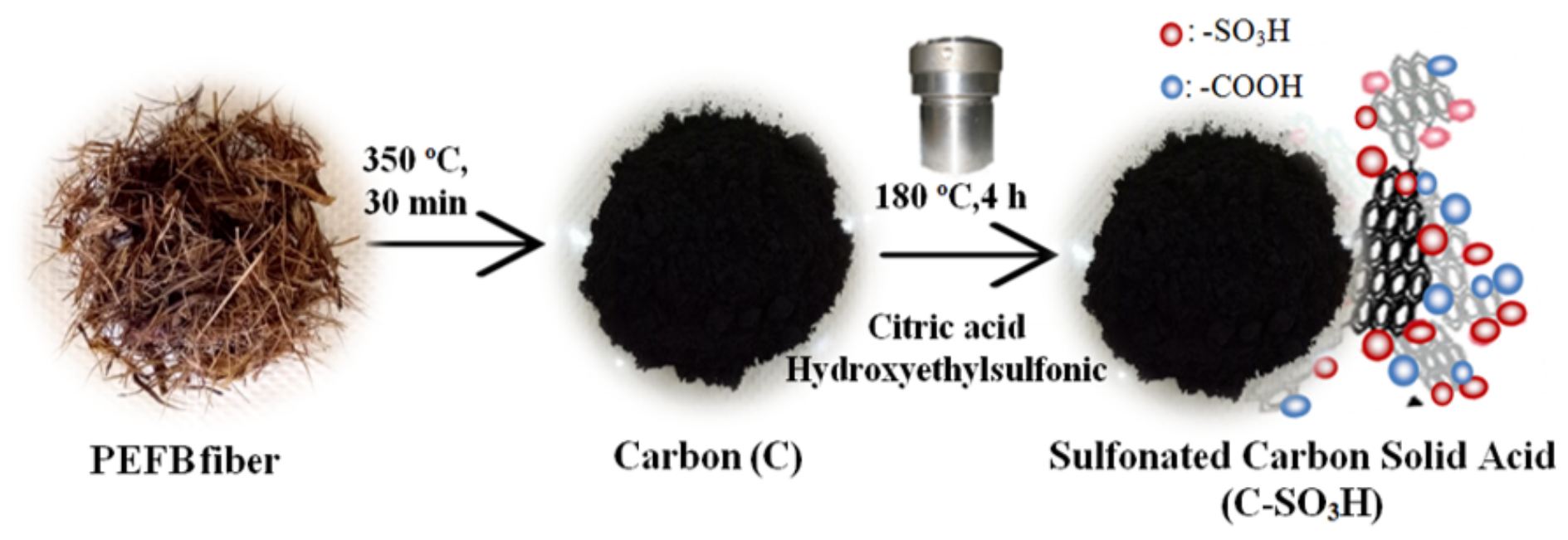

Figure 1

Preparation steps of C-SO3H generated from PEFB 

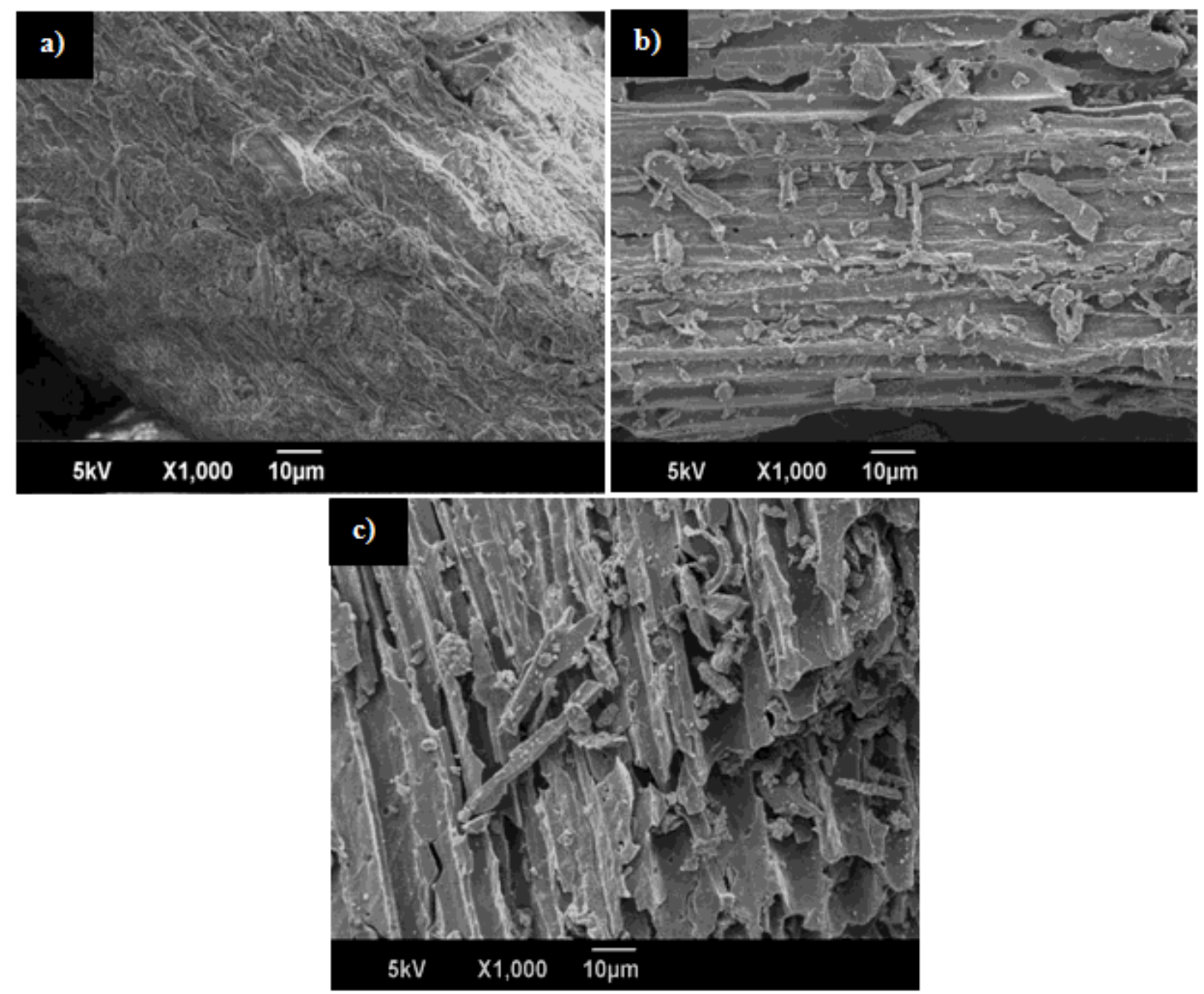

Figure 2

SEM images of (a) palm empty fruit bunch (PEFB); (b) PEFB after carbonization and (c) sulfonated carbon solid acid catalyst (C-SO3H). 


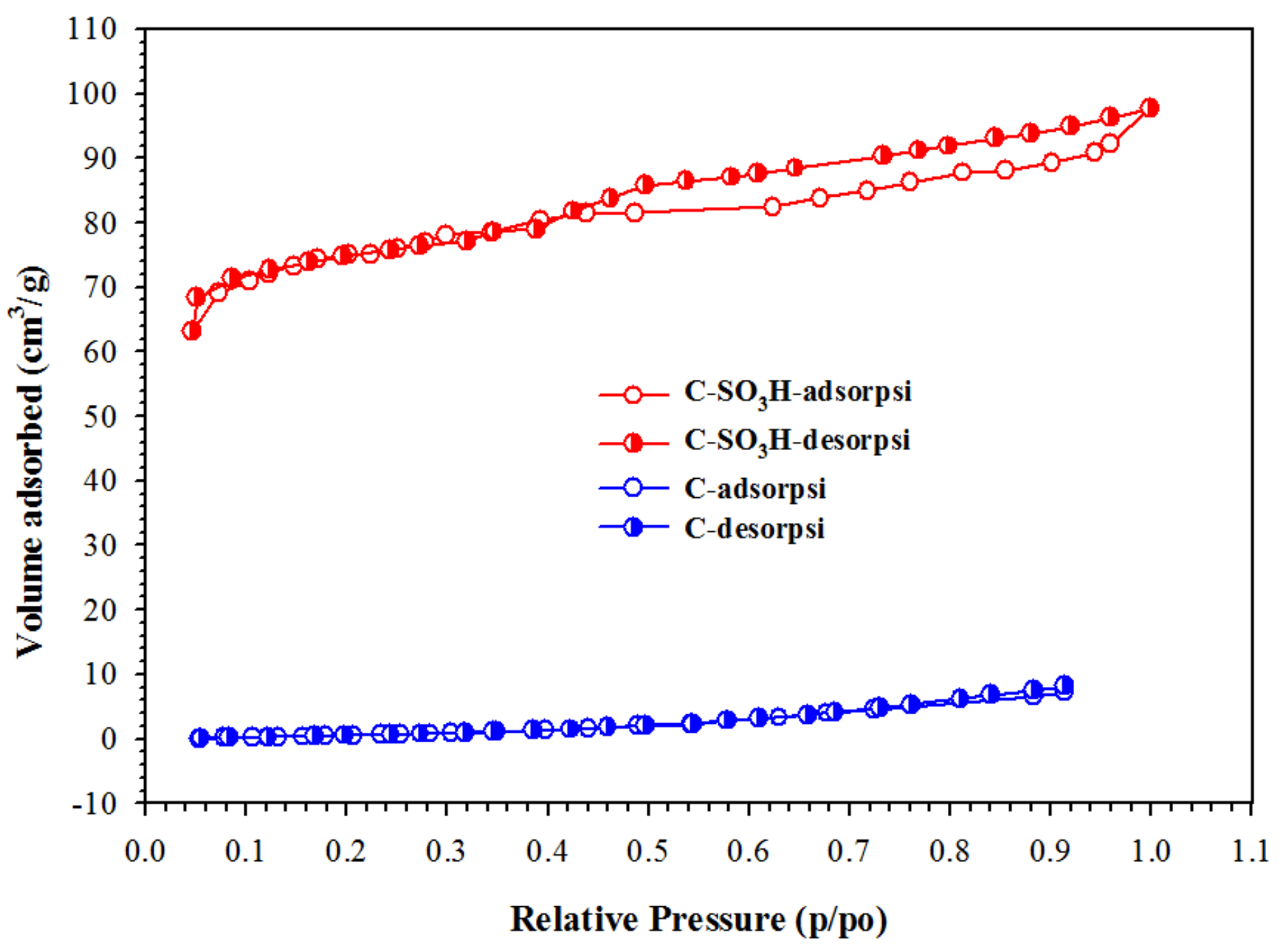

Figure 3

The nitrogen adsorption-desorption isotherm of PEFB after carbonization (C) and sulfonated carbon solid acid catalyst (C-SO3H). 


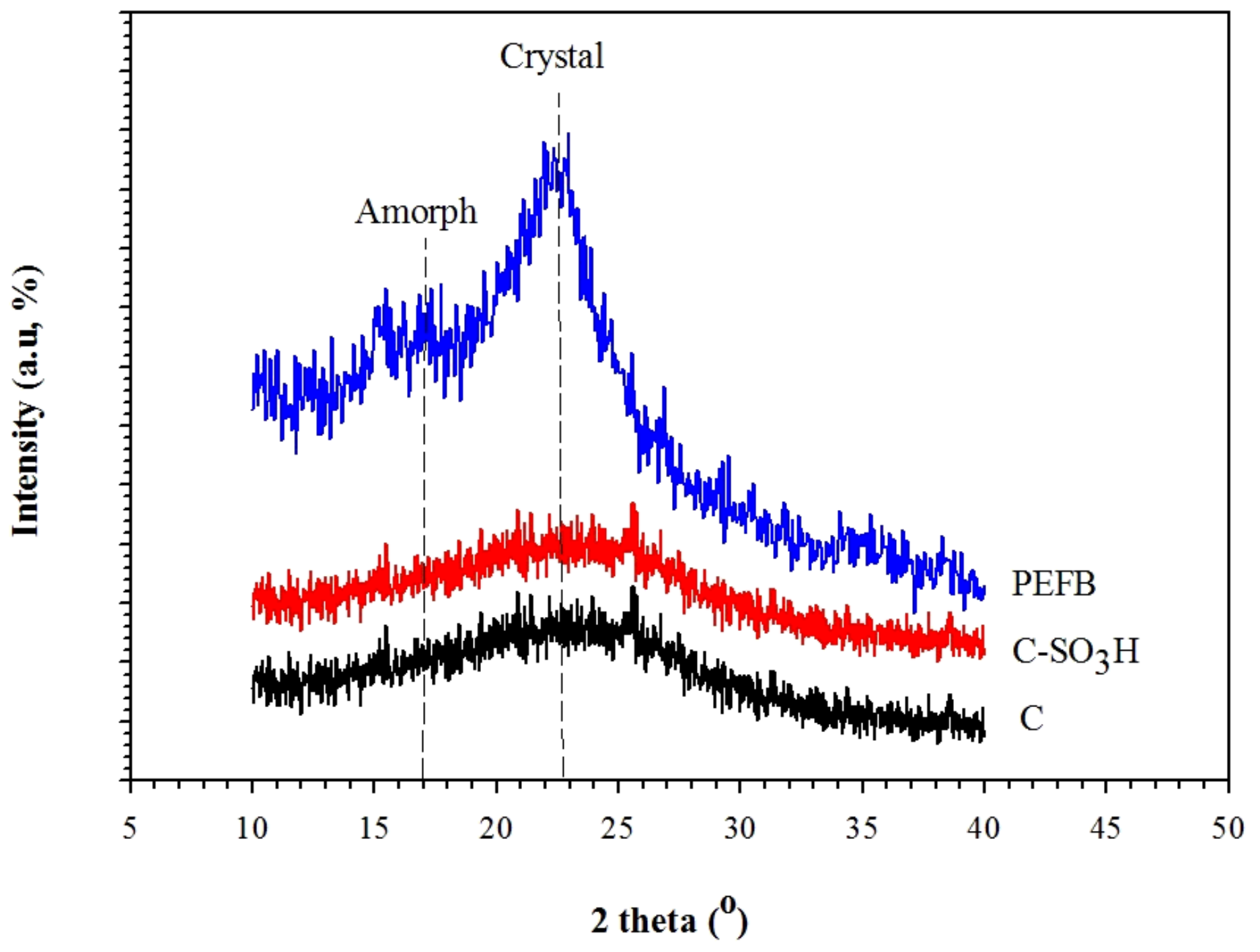

Figure 4

XRD pattern of $\mathrm{PEFB}, \mathrm{C}$ and $\mathrm{C}-\mathrm{SO} 3 \mathrm{H}$ 


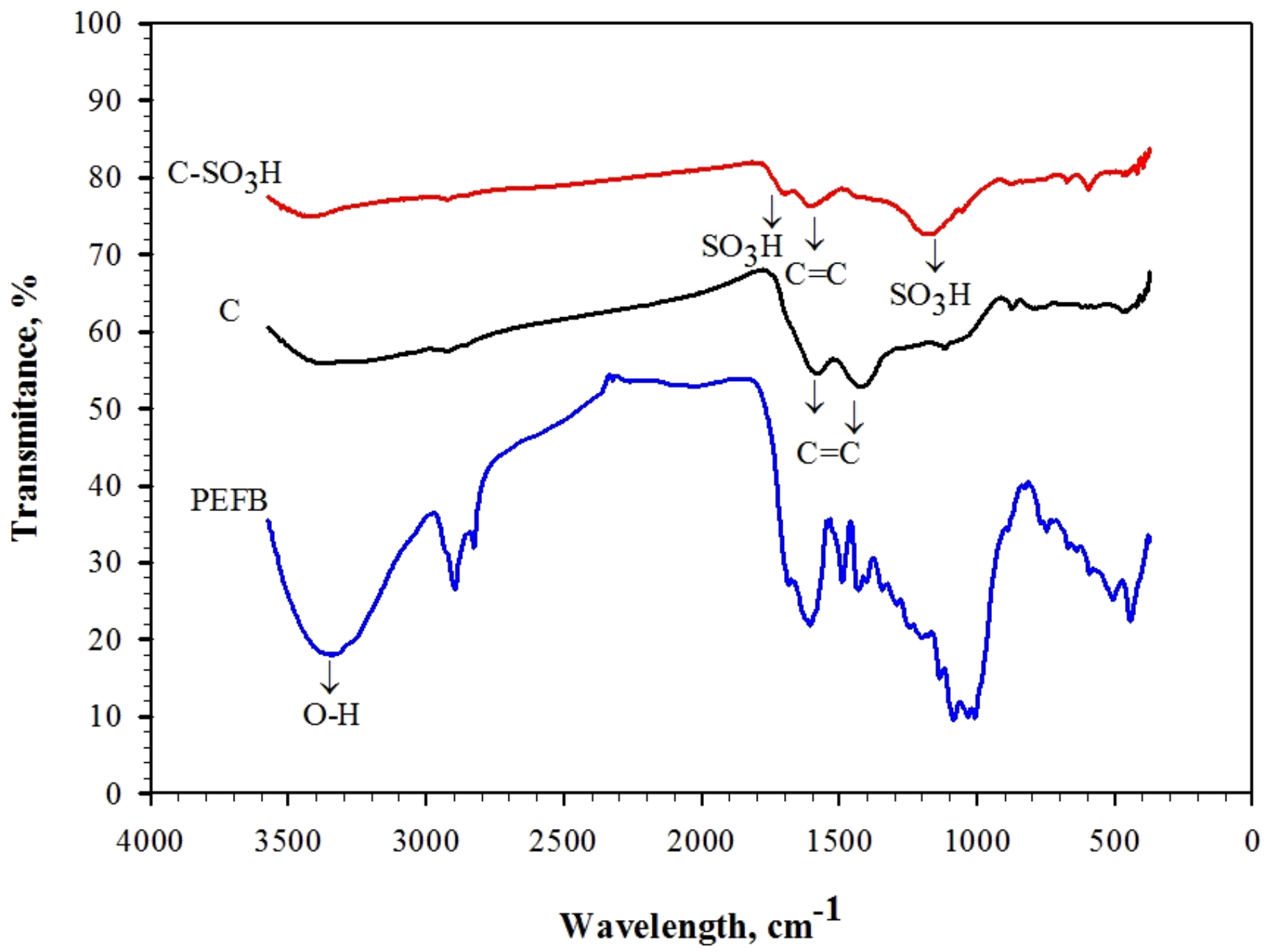

Figure 5

FT-IR spectra of PEFB, C and C-SO3H 


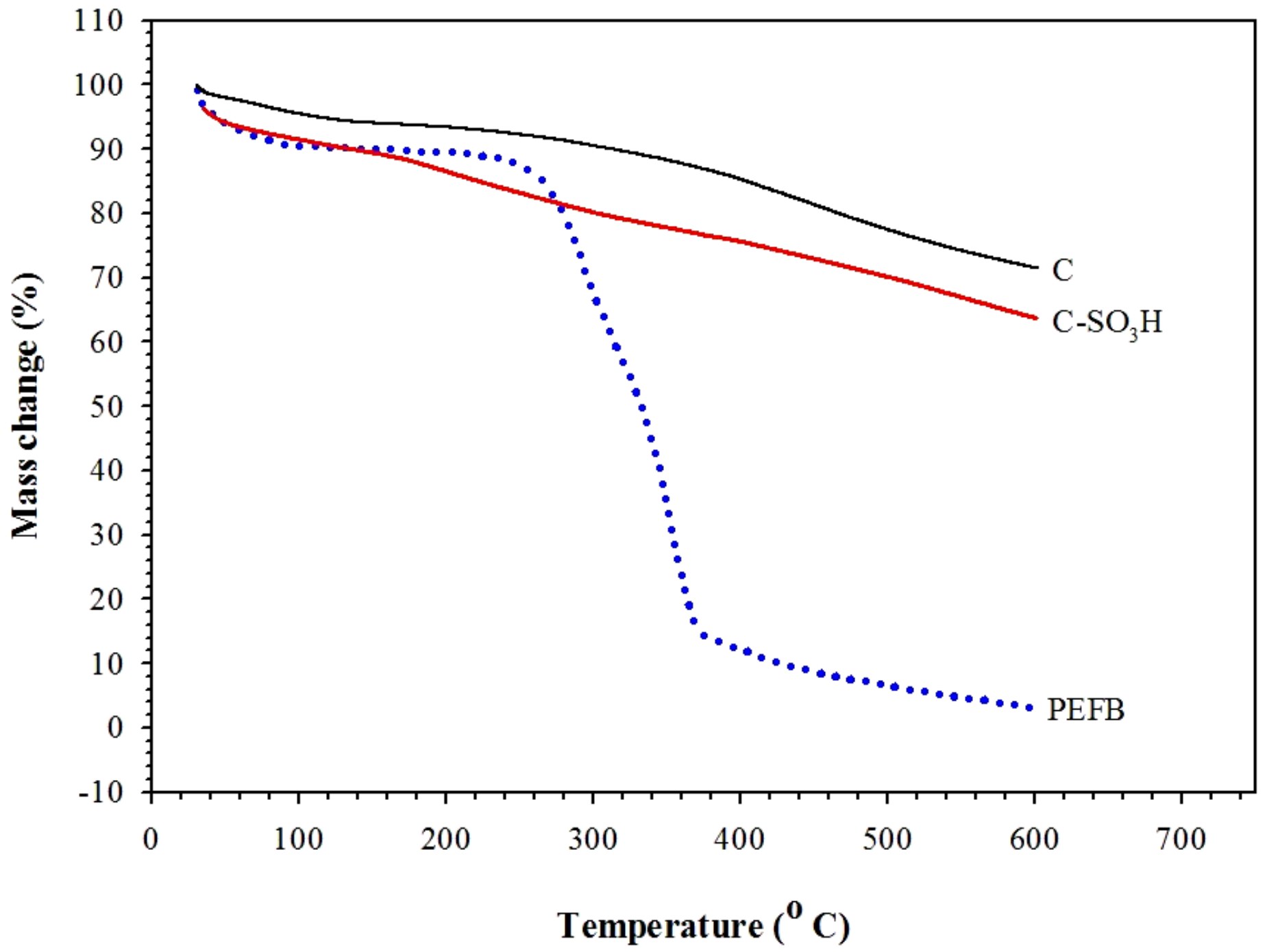

Figure 6

Thermal gravimetric analysis curve of PEFB, C, and C-SO3H 


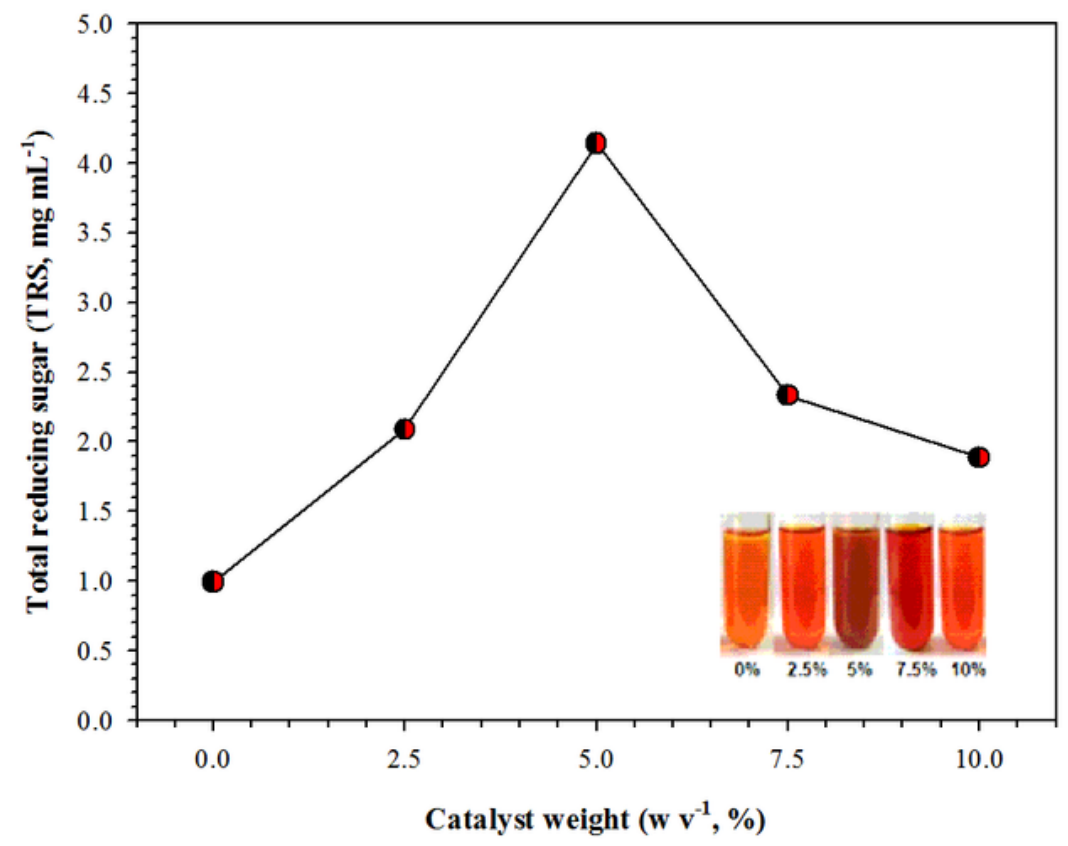

Figure 7

Total reducing sugar (TRS) of cassava peels starch hydrolysis on variation of C-SO3H as catalyst weight. Reaction condition: $5 \%(\mathrm{w} / \mathrm{v})$ of cassava peel starch, $100 \mathrm{oC}, 1 \mathrm{~h}$. 


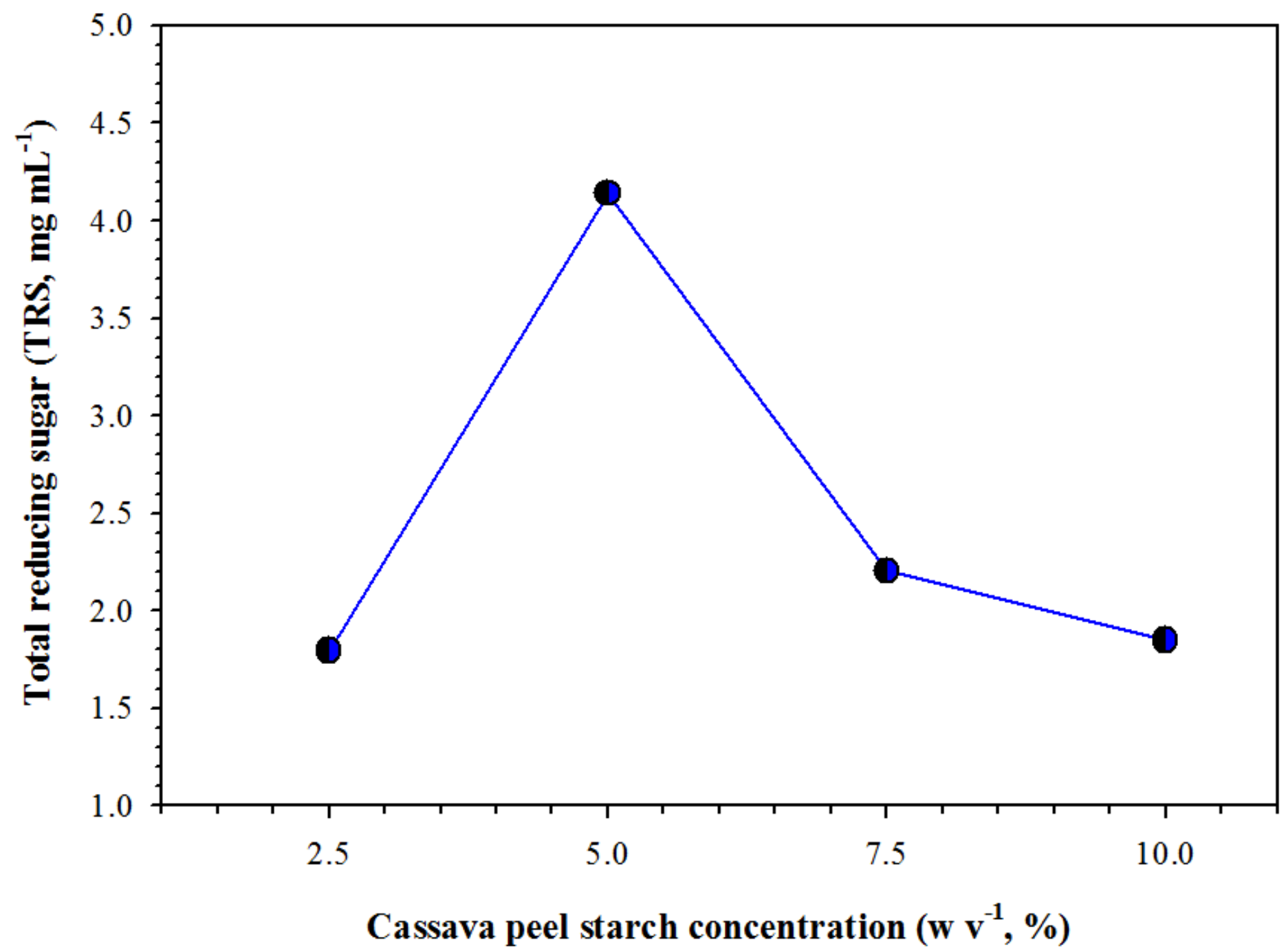

Figure 8

Total reducing sugar (TRS) of cassava peels starch hydrolysis on variation of cassava peel starch concentrations. Reaction condition: 5\% (w/v) of C-SO3H, $100 \mathrm{oC}, 1 \mathrm{~h}$. 


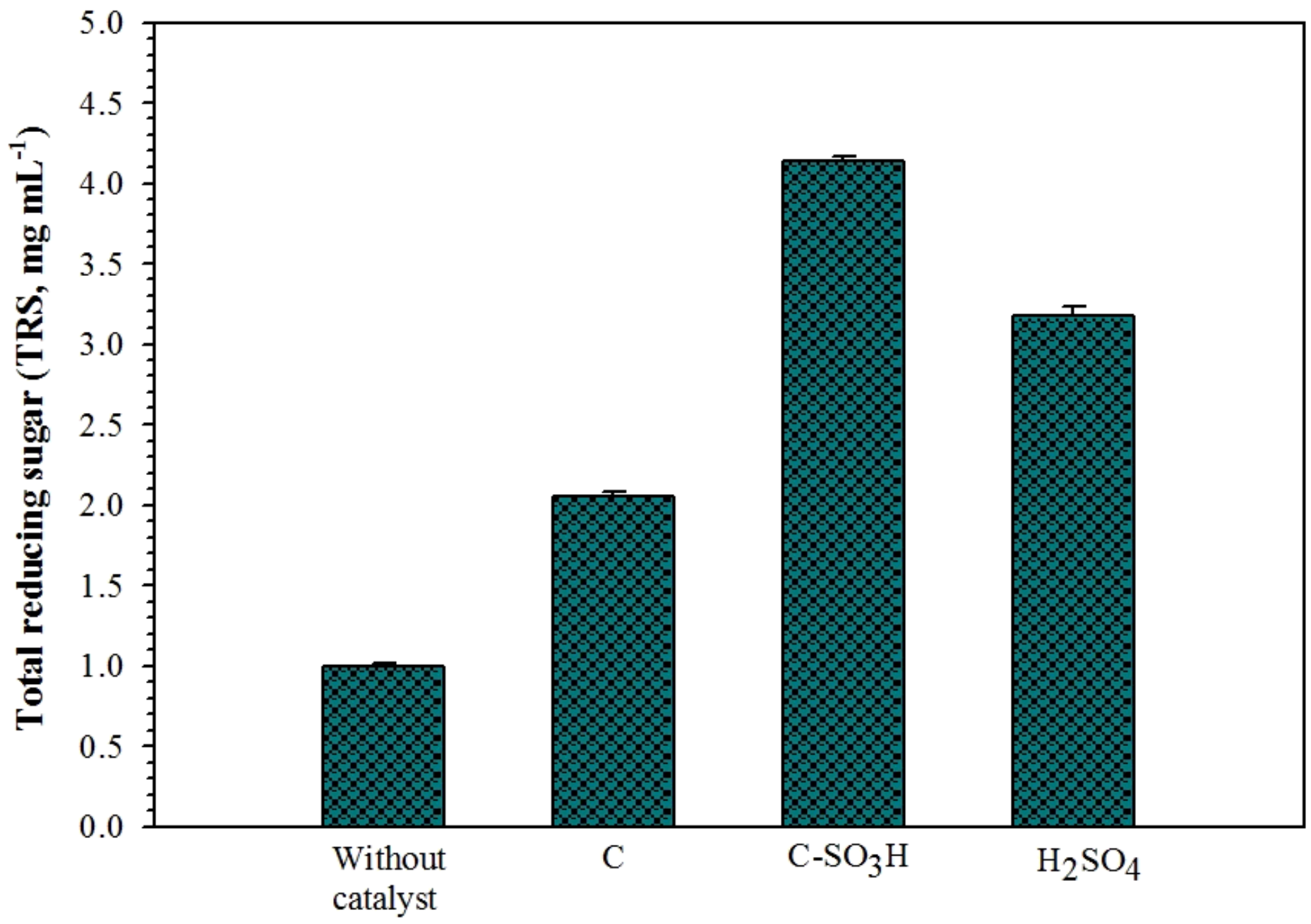

Type of catalyst

Figure 9

Total reducing sugar (TRS) of cassava peels starch hydrolysis over different catalyst type. Reaction condition: $5 \%(\mathrm{w} / \mathrm{v})$ of cassava peel starch and C SO3H , $100 \mathrm{oC}, 1 \mathrm{~h}$. 


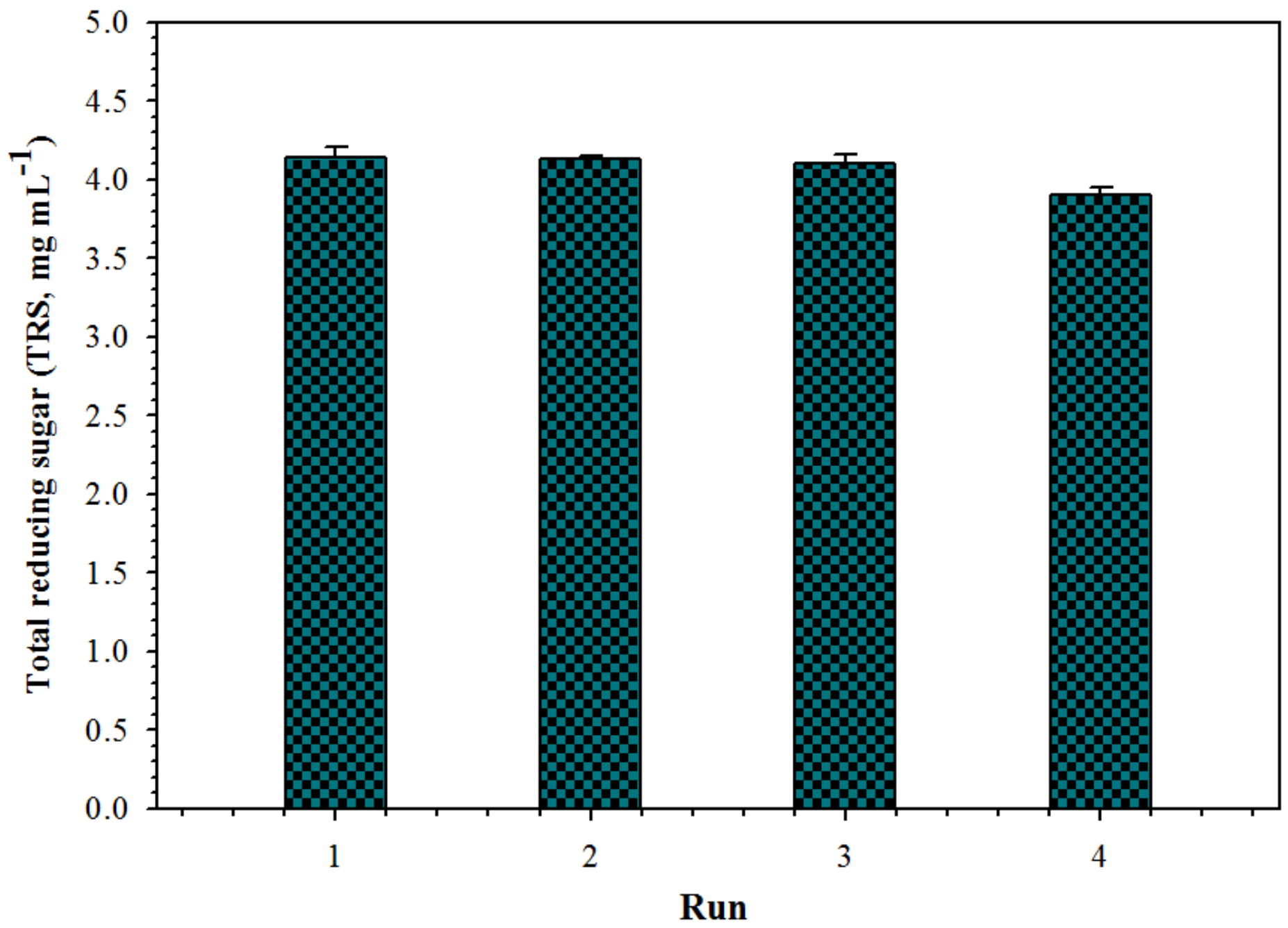

Figure 10

Catalytic performance of C-SO3H during 4th repeated used of cassava peel starch hydrolysis. Reaction condition: $5 \%(\mathrm{w} / \mathrm{v})$ of cassava peel starch and C-SO3H, $100 \mathrm{oC}, 1 \mathrm{~h}$. 